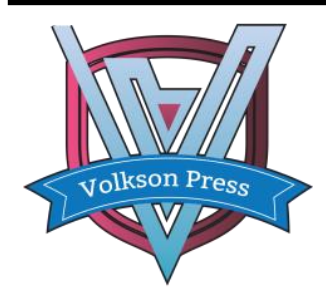

Contents List available at VOLKSON PRESS

Engineering \& Technology Innovations (ETI)

DOI : http://doi.org/10.26480/iceti.01.2017.105.108

\title{
POST-EVALUATION OF THE ENERGY TRUSTEESHIP PROJRCT OF REGIONAL DISTRIBUTION NETWORK
}

\author{
Yuzhen Zhou*, He Wang, Ting Xie, Lei Liu \\ State Grid Energy Conservation Service Co.,Ltd.,Beijing 100052, China \\ *pengyongbj@163.com
}

This is an open access article distributed under the Creative Commons Attribution License, which permits unrestricted use, distribution, and reproduction in any medium, provided the original work is properly cited

\section{ARTICLE DETAILS}

\section{Article History:}

Received 02 october 2017 Accepted 06 october 2017

Available online 11 october 2017

Keywords:

Regional distribution network, Energy trusteeship mode, Postevaluation

\section{ABSTRACT}

In recent years, Chinese government put more emphasis on the energy conservation and emissions reduction of power system, the power enterprises and energy-saving service companies began to pay attention to the application of energy performance contracting in the energy-saving reconstructs of the regional distribution network. The energy trusteeship is a perfect mode for prompting the diminishing line loss and economizing power energy of regional distribution network. In order to evaluate the implementation effect of the energy trusteeship project of regional distribution network, the paper designed the post-evaluation index system from the four stages, namely, decision-making stage, preparation phase, implementation stage and operation phase, based on the lifecycle theory; And then used the analytic hierarchy process to calculate the weight of post-evaluation index; Finally, the postevaluation model of the energy trusteeship project of regional distribution network was constructed. The postvaluation mode contributed to improve the investment efficiency for the future energy trusteeship projects of regional distribution system.

\section{INTRODUCTION}

With the application of energy performance contracting (EPC) in regional distribution network, as an important mode of EPC, the energy trusteeship mode promoted the innovation and development of the energy saving service mode of electrical network operation [1,2]. At present, only few literatures researched the energy trusteeship mode, especially its post evaluation. Most scholars were mainly focus on large-scale power grid construction and evaluation on the improved construction project. As for the evaluation of large-scale power engineering projects, the analytic hierarchy process (AHP) method, Delphi method, fuzzy comprehensive evaluation and other methods were often used. These methods were able to evaluate these sub-projects rapidly and accurately. Based on these, the logical framework method was used to do further comprehensive analysis. It can take fully advantage of the overall approach and avoid the shortcomings of single method [3-6].

The indicator system is the foundation of post evaluation model, and many literatures designed the evaluation index system. Lu Lei indicated that the index system should be designed based on the principles of comprehensive, simplicity, relative independence, and objectivity $[7,8]$. The weights are the key factors that influence the project evaluation, and the index weight was determined by the analytic hierarchy method level $[9,10]$. Based on that, the paper would design the post-evaluation index system, obtain the judgment matrixes of weights based on the AHP and the post evaluation experience, and then estimate the post evaluation index weights. Finally the paper constructed the post evaluation mode of the energy trusteeship of regional distribution network.

\section{The design of post evaluation index system}

The energy trusteeship project of regional distribution network can be divided into four stages based on the project cycle theory, namely the stage of decision-making, preparation, energy-saving renovation and operation. The paper designed the post-evaluation index system based on these four stages, in order to evaluate the process and effect of the energy trusteeship project implementation of regional distribution system objectively and scientifically.

\subsection{The decision-making stage}

Although the cost of the project decision-making phase is not high, it takes comparatively long time to complete the project establishment work in the stage. The process and quality of the work in the stage has an important influence on the project investment benefit and even determine if the project is a success or a failure. Therefore, the post-evaluation of the decision-making stage $\left(B_{1}\right)$ is an important part of project overall postevaluation.

The post-evaluation index system of the decision-making stage was designed from the three dimensions of the scheme drafting capacity $\left(S D C_{-} C_{11}\right)$, project deciding capacity $\left(P D C_{-} C_{12}\right)$ and plan implementation capacity $\left(P I C_{-} C_{13}\right)$. The specific post-evaluation indexes of the three dimensions were shown in the Table 1.

Table 1. Post-evaluation index system of the decision-making stage

\begin{tabular}{cc}
\hline Dimension & post-evaluation index \\
& loss reduction estimation accuracy rate $(L E R)$ \\
& investment estimation accuracy rate $(I E R)$ \\
$S D C_{-} C_{11}$ & Loss reduction scheme responsivity $(L S R)$ \\
& goal achievement rate $(G A R)$ \\
$P D C_{-} C_{12}$ & project alteration rate $(P A R)$ \\
$P I C_{-} C_{13}$ & project completion rate $(P C R)$ \\
\hline
\end{tabular}

\subsection{The preparation stage}

The preparation stage determines the quality of the project implementation preparation work and affects the construction and operation of the energy trusteeship project of regional distribution network. Orderly and scientific preparation work contributes to the smooth implementation of the project. So the post-evaluation of the preparation stage $\left(B_{2}\right)$ is an important part of the project overall postevaluation. 
The paper designed the post-evaluation index system of the preparation stage based on the project program design $\left(P P D_{-} C_{21}\right)$, project bidding and tendering $\left(P B T_{-} C_{22}\right)$, project investment and financing $\left(P I F_{-} C_{23}\right)$ and project start preparation $\left(P S P_{-} C_{24}\right)$. The specific post-evaluation indexes of the above four dimensions were shown in the Table 2.

Table 2. Post-evaluation index system of the preparation stage

\begin{tabular}{cc}
\hline Dimension & post-evaluation index \\
\hline$P P D_{-} C_{21}$ & program design depth $(P S D)$ \\
$P B T_{-} C_{22}$ & $\begin{array}{c}\text { program construction instructions }(P C D) \\
\text { investment and financing program }(I F P) \\
\text { project-funding preparations }(P F P) \\
\text { project bidding work }(P B W) \\
\text { project tendering work }(P T W) \\
\text { contract signature }(C T S) \\
P S P_{-} C_{24}\end{array}$ \\
\hline
\end{tabular}

2.3 The energy-saving renovation stage

In the energy-saving renovation stage, the participants need to devote a large sum of utilize human, material and financial resources, and the management in the phase is important to the project performance. Therefore, the post-evaluation of the energy-saving renovation stage $\left(B_{3}\right)$ is the indispensable portion in the project overall post-evaluation.

In order to evaluate the implementation work, the post-evaluation index system of the implementation stage was designed from the five dimensions of the Project schedule control $\left(P S C_{-} C_{31}\right)$, Project quality control $\left(P Q C_{-} C_{32}\right)$, Project Investment Control $\left(P I C_{-} C_{33}\right)$, Project Safety Management $\left(P S M_{-} C_{33}\right)$, and Project contract management $\left(P C M_{-} C_{35}\right)$. The specific post-evaluation indexes of the five dimensions were shown in the Table 3.

Table 3. Post-evaluation index system of the energy-saving renovation stage

\begin{tabular}{|c|c|}
\hline Dimension & post-evaluation index \\
\hline$P S C_{-} C_{31}$ & percentage complete on schedule (PCS) \\
\hline$P Q C_{-} C_{32}$ & control point detection pass rate $(C D R)$ \\
\hline$P I C_{-} C_{33}$ & $\begin{array}{l}\text { cost change rate }(C C R) \\
\text { fund payment and management }(F P M)\end{array}$ \\
\hline$P S M_{-} C_{34}$ & $\begin{array}{l}\text { equipment safety management (ESM) } \\
\text { person safety management }(P S M)\end{array}$ \\
\hline$P C M_{-} C_{35}$ & $\begin{array}{l}\text { contract terms implementation (CTI) } \\
\text { contract terms modification (CTM) }\end{array}$ \\
\hline
\end{tabular}

\subsection{The operation stage}

The state of operation is the most able to reflect the project implementation effect of the energy trusteeship projects of regional distribution system directly. So the post-evaluation of the operation stage $\left(B_{4}\right)$ is the a key component of the project overall post-evaluation.

The post-evaluation index system of the operation phase was designed from the six dimensions of the project financial benefits $\left(P F B_{-} C_{41}\right)$, energysaving environmental benefits $\left(E E B_{-} C_{42}\right)$, project social benefits $\left(P S B_{-} C_{43}\right)$, distribution network security $\left(D N S_{-} C_{44}\right)$, distribution network operation $\left(D N O_{-} C_{45}\right)$, project operation and management $\left(P O M_{-} C_{46}\right)$. The specific post-evaluation indexes of the above six dimensions were shown in the Table 4.

Table 4. Post-evaluation index system of the operation stage Dimension post-evaluation index internal rate of return $(I R R)$

PFB_C 4 41 investment payback period $(I P O)$ net present value $(N P V)$ investment profit ratio $(I P R)$ loss reduction rate $(L R R)$, power loss reduction $(P L R)$

$E E B_{-} C_{42}$ saving transformers proportion $(E T P)$ employment contribution $(E C N)$

$P_{3} C_{43} \quad$ energy-saving technology improvement (ETI)

promoting economic development $(P E D)$ voltage qualified rate $(V Q R)$ power supply reliability $(P S R)$;

$D N S_{-} C_{44}$

DNO_C 45 power equipment management (PEM) energy measurement management $(E M M)$ energy-saving management (ESM) reactive power compensation capability $(R P C)$

$P O M_{-} C_{46}$ power load stability $(P L S)$ transformer load rate (TLR).

\subsection{The post-evaluation index system}

The post-evaluation index system of the energy trusteeship project of the regional distribution network $\left(N T P_{-} R D N\right)$ was constructed on basis of selecting the forty post-evaluation indexes from the four stages of the decision-making, preparation, energy-saving renovation and operation. The post-evaluation index system was shown in the Fig. 1.

Fig1. Post-evaluation index system of the NTP_RDN

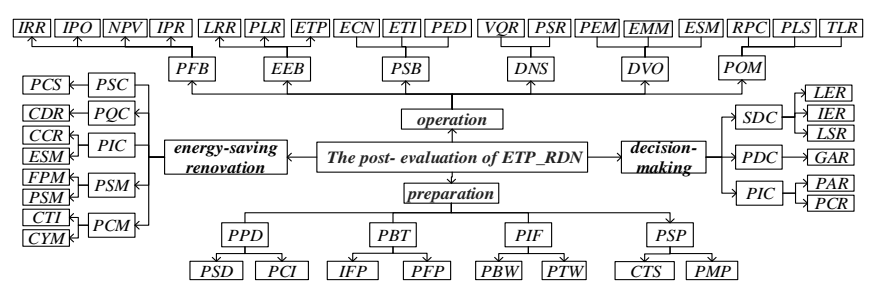

3. The post-evaluation model construction of the regional distribution network energy trusteeship project

On the basis of the designing of post-evaluation index system, the experts and scholars, technical personnel and management personnel of the relevant areas was chose to investigate the relative importance of post evaluation indexes in the form of questionnaires, and collected the evaluation data of the post-evaluation indexes of the energy trusteeship project of the regional distribution network. The paper sorted out the weight judgment matrix of post-evaluation indexes by analyzing the evaluation data based on the AHP.

\subsection{The first-level post-evaluation index weight}

The first-order index weight judgment matrix $A-B$ of post-evaluation:

$$
A-B=\left|\begin{array}{ccc}
1 & 3 & 1 / 2 \\
1 / 3 & 1 & 1 / 3 \\
2 & 3 & 1 \\
2 & 3 & 1
\end{array}\right|
$$

The paper used the MATLAB to calculate the first-level index weight of the post-evaluation of the energy trusteeship project of regional distribution network, the result is as follow:

$$
W^{(1)}=(0.2094,0.0982,0.3462,0.3462)
$$

The consistency test index of the weight judgment matrix is 0.023 , and less than 0.1 , which indicates that the weight judgment matrix satisfies the consistency test, and the weight calculation result is scientific and reliable 3.2 The second-level evaluation index weight

The second-level index weight judgment matrix $B_{1}-C$ of the decisionmaking stage post-evaluation:

$$
B_{1}-C=\left|\begin{array}{ccc}
1 & 1 / 2 & 1 / 2 \\
2 & 1 & 1 / 2 \\
2 & 2 & 1
\end{array}\right|
$$

The second-level index weight judgment matrix $B_{2}-C$ of the preparation stage post-evaluation:

$$
B_{2}-C=\left|\begin{array}{cccc}
1 & 2 & 3 & 4 \\
1 / 2 & 1 & 3 & 3 \\
1 / 3 & 1 / 3 & 1 & 2 \\
1 / 4 & 1 / 3 & 1 / 2 & 1
\end{array}\right|
$$

The second-level index weight judgment matrix $B_{3}-C$ of the energysaving renovation stage post-evaluation:

$$
B_{3}-C=\left|\begin{array}{ccccc}
1 & 1 / 3 & 1 / 2 & 1 / 2 & 1 \\
3 & 1 & 2 & 2 & 3 \\
2 & 1 / 2 & 1 & 1 / 2 & 2 \\
2 & 1 / 2 & 2 & 1 & 2 \\
1 & 1 / 3 & 1 / 2 & 1 / 2 & 1
\end{array}\right|
$$


The second-level index weight judgment matrix $B_{4}-C$ of the operation stage post-evaluation:

$$
B_{4}-C=\left|\begin{array}{cccccc}
1 & 3 & 2 & 2 & 2 & 4 \\
1 / 3 & 1 & 1 / 2 & 1 / 3 & 1 / 2 & 3 \\
1 / 2 & 2 & 1 & 1 / 2 & 2 & 4 \\
1 / 2 & 3 & 2 & 1 & 2 & 4 \\
1 / 2 & 2 & 1 / 2 & 1 / 2 & 1 & 3 \\
1 / 4 & 1 / 3 & 1 / 4 & 1 / 4 & 1 / 3 & 1
\end{array}\right|
$$

And then used MATLAB to calculate the second-level index weights of the post-evaluation of the decision-making stage, preparation phase, energysaving renovation stage and operation phase respectively, the results are as follow:

$W_{1}^{(2)}=(0.196,0.311,0.493)$

$W_{2}^{(2)}=(0.459,0.305,0.143,0.093)$

$W_{3}^{(2)}=(0.108,0.365,0.180,0.239,0.108)$

$W_{4}^{(2)}=(0.305,0.093,0.178,0.241,0.134,0.049)$

The consistency test index of the above four weight judgment matrixes is:

$$
C R=C I / R I=(0.052,0.030,0.016,0.032)
$$

The consistency test indexes of the above weight judgment matrixes are less than 0.1. Therefore, the consistency tests of the four judgment matrixes could be adopted, and the calculation result of post-evaluation indexes weight is scientific and reliable.

\subsection{The third-level evaluation index weight}

(1) The decision-making stage

The third-order index weight judgment matrix $C_{11}-D$ and $C_{13}-D$ of the post-evaluation of the scheme drafting capacity and plan implementation capacity are as follow:

$C_{11}-D=\left|\begin{array}{ccc}1 & 2 & 3 \\ 1 / 2 & 1 & 2 \\ 1 / 3 & 1 / 2 & 1\end{array}\right| \quad C_{13}-D=\left|\begin{array}{cc}1 & 1 / 2 \\ 2 & 1\end{array}\right|$

And then used MATLAB to calculate the third-order index weights of the post-evaluation of the scheme drafting capacity and plan implementation capacity respectively, the results are as follow:

$$
W_{11}^{(3)}=(0.540,0.297,0.163) \quad W_{13}^{(3)}=(0.333,0.667)
$$

The consistency test index of the weight judgment matrix $C_{11}-D$ is $C R=C I / R I=0.0089<0.1$. The calculation result is reliable. The weight judgment matrix $C_{13}-D$ doesn't need consistency check. As for the dimension of project deciding capacity has only a third-order index, so the GAR index weight is $W_{12}^{(3)}=(1.000)$

(2) The preparation stage

The third-order index weight judgment matrix $C_{21}-D, C_{22}-D$,

$C_{23}-D$ and $C_{24}-D$ of the post-evaluation of project program design, project bidding and tendering, project investment and financing and project start preparation are as follow:

$$
\begin{aligned}
C_{21}-D=\left|\begin{array}{cc}
1 & 2 \\
1 / 2 & 1
\end{array}\right| & C_{22}-D=\left|\begin{array}{cc}
1 & 1 \\
1 & 1
\end{array}\right| \\
C_{23}-D=\left|\begin{array}{cc}
1 & 1 / 2 \\
2 & 1
\end{array}\right| & C_{24}-D=\left|\begin{array}{cc}
1 & 1 / 2 \\
2 & 1
\end{array}\right|
\end{aligned}
$$

$W_{23}^{(3)}=(0.333,0.667) \quad W_{23}^{(3)}=(0.333,0.667)$

The above four weight judgment matrix doesn't need consistency check. (3) The energy-saving renovation stage

The third-order index weight judgment matrix $C_{33}-D, C_{34}-D$ and $C_{35}-D$ of post-evaluation of the project program design, project bidding and tendering, project investment and financing and project start preparation are as follow:

$$
C_{33}-D=\left|\begin{array}{cc}
1 & 2 \\
1 / 2 & 1
\end{array}\right| \quad C_{34}-D=\left|\begin{array}{cc}
1 & 1 / 2 \\
2 & 1
\end{array}\right| \quad C_{35}-D=\left|\begin{array}{cc}
1 & 3 \\
1 / 3 & 1
\end{array}\right|
$$

The weight calculation results are as follow:

$$
\begin{aligned}
& W_{33}^{(3)}=(0.667,0.333) \quad W_{34}^{(3)}=(0.333,0.667) \\
& W_{35}^{(3)}=(0.750,0.250)
\end{aligned}
$$

The dimensions of the Project schedule control and project quality control have only a third-order index respectively, so the index weight of both PCS and $C D R$ are as follow:

$W_{31}^{(3)}=W_{32}^{(3)}=(1.000)$

(4) The operation stage

The third-order index weight judgment matrix $C_{41}-D, C_{42}-D$, $C_{43}-D, C_{44}-D, C_{45}-D$ and $C_{46}-D$ of the project financial benefits, energy-saving environmental benefits, project social benefits, distribution network security, distribution network operation, project operation and management are as follow:

$$
\begin{aligned}
C_{41}-D & =\left|\begin{array}{cccc}
1 & 2 & 2 & 2 \\
1 / 2 & 1 & 1 / 2 & 1 / 2 \\
1 / 2 & 2 & 1 & 1 / 2 \\
1 / 2 & 2 & 2 & 1
\end{array}\right| C_{42}-D=\left|\begin{array}{ccc}
1 & 2 & 3 \\
1 / 2 & 1 & 2 \\
1 / 3 & 1 / 2 & 1
\end{array}\right| \\
C_{43}-D & =\left|\begin{array}{ccc}
1 & 2 & 3 \\
1 / 2 & 1 & 2 \\
1 / 3 & 1 / 2 & 1
\end{array}\right| C_{44}-D=\left|\begin{array}{cc}
1 & 1 / 2 \\
2 & 1
\end{array}\right| \\
C_{45}-D & =\left|\begin{array}{ccc}
1 & 2 & 3 \\
1 / 2 & 1 & 2 \\
1 / 3 & 1 / 2 & 1
\end{array}\right| C_{46}-D=\left|\begin{array}{ccc}
1 & 1 / 2 & 1 / 2 \\
2 & 1 & 1 / 2 \\
2 & 2 & 1
\end{array}\right|
\end{aligned}
$$

The weight calculation results are as follow:

$$
\begin{aligned}
& W_{41}^{(3)}=(0.391,0.138,0.195,0.276) \\
& W_{42}^{(3)}=(0.333,0.528,0.140) \\
& W_{43}^{(3)}=(0.163,0.540,0.297) \\
& W_{44}^{(3)}=(0.333,0.667) \\
& W_{45}^{(3)}=(0.333,0.667) \\
& W_{46}^{(3)}=(0.196,0.311,0.493)
\end{aligned}
$$

The consistency test indexes of the above judgment matrices are less than 0.1 , so the results are scientific and reliable.

\subsection{The post-evaluation model}

According to the calculation result of post-evaluation index weight, the post-evaluation model of the energy trusteeship project of the regional distribution network was obtained:

The weight calculation results are as follow:

$W_{21}^{(3)}=(0.667,0.333) \quad W_{22}^{(3)}=(0.500,0.500)$ 
Post evaluation $(A)=W^{(1)} \bullet B$

$=(0.209,0.098 .0 .346,0.346) \bullet\left(B_{1}, B_{2}, B_{3}, B_{4}\right)^{T}$

$=0.209 \times B_{1}+0.098 \times B_{2}+0.346 \times B_{3}+0.346 \times B_{4}$

(1) The post-evaluation sub model of decision-marking stage ( $B_{1}$ ):

Decision-marking post-evaluation $\left(B_{1}\right)=W_{1}^{(2)} \bullet C_{1}^{T}$

$=0.196 \times S D C_{-} C_{11}+0.311 \times P D C_{-} C_{12}+0.493 \times P I C_{-} C_{13}$

Where,

$$
\begin{aligned}
S D C_{-} C_{11} & =W_{11}^{3} \bullet D_{11}^{T} \\
& =0.540 \times L E R+0.297 \times I E R+0.163 \times L S R \\
P D C_{-} C_{12} & =1.000 \times G A R \\
P I C_{-} C_{13} & =W_{13}^{3} \bullet D_{13}^{T} \\
& =0.333 \times P A R+0.667 \times P C R
\end{aligned}
$$

(2) The post-evaluation sub model of preparation stage ( $\left.B_{2}\right)$ :

$$
\begin{aligned}
& \text { Preparation post-evaluation }\left(B_{2}\right)=W_{2}^{(2)} \bullet C_{2}^{T} \\
& =0.459 \times P P D_{-} C_{21}+0.305 \times P B F_{-} C_{22} \\
& +0.143 \times P I T \_C_{23}+0.093 \times P S P \_C_{24}
\end{aligned}
$$

Where,

$$
\begin{aligned}
P P D_{-} C_{21} & =W_{21}^{3} \bullet D_{21}^{T} \\
& =0.667 \times P S D+0.333 \times P C I \\
P B{ }_{-} C_{22} & =W_{22}^{3} \bullet D_{22}^{T} \\
& =0.5 \times I F P+0.5 \times P F P \\
P I F \_C_{23} & =W_{23}^{3} \bullet D_{23}^{T} \\
& =0.667 \times P B W+0.333 \times P T W \\
P S P \_C_{24} & =W_{24}^{3} \bullet D_{24}^{T} \\
& =0.667 \times C T S+0.333 \times P M P
\end{aligned}
$$

(3) The post-evaluation sub model of energy-saving renovation stage $\left(B_{3}\right)$ :

Energy - saving renovation post-evaluation $\left(B_{3}\right)=W_{3}^{(2)} \bullet C_{3}^{T}$

$=0.108 \times P S C_{-} C_{31}+0.365 \times P Q C_{-} C_{32}$

$+0.180 \times P I C \_C_{33}+0.239 \times P S M{ }_{-} C_{34}+0.108 \times P C M_{-} C_{35}$

Where,

$$
\begin{aligned}
P S C_{-} C_{31} & =1.000 \times P C S \\
P Q C_{-} C_{32} & =1.000 \times C D R \\
P I C_{-} C_{33} & =W_{33}^{3} \bullet D_{33}^{T} \\
& =0.667 \times C C R+0.333 \times F P M \\
P S M_{-} C_{34} & =W_{34}^{3} \bullet D_{34}^{T} \\
& =0.333 \times E S M+0.667 \times P S M \\
P C M_{-} C_{35} & =W_{3,5}^{3} \bullet D_{35}^{T} \\
& =0.75 \times C P M+0.25 \times C O C
\end{aligned}
$$

(4) The post-evaluation sub model of operation stage ( $\left.B_{4}\right)$ :

$$
\begin{aligned}
& \text { Operation post-evaluation }\left(B_{4}\right)=W_{4}^{(2)} \bullet C_{4}^{T} \\
& =0.305 \times P F B_{-} C_{41}+0.093 \times E E B_{-} C_{42} \\
& +0.178 \times P S B \_C_{43}+0.241 \times D N S_{-} C_{44} \\
& +0.134 \times D N O{ }_{-} C_{45}+0.049 \times P O M \_C_{46}
\end{aligned}
$$

Where,

$$
\begin{aligned}
& P F B_{-} C_{41}=W_{41}^{3} \bullet D_{41}^{T} \\
& =0.391 \times I R R+0.138 \times I P O+0.195 \times N P V+0.276 \times I P R \\
& E E B_{-} C_{42}=W_{42}^{3} \bullet D_{42}^{T} \\
& =0.333 \times L R R+0.528 \times P L R+0.140 \times E T P \\
& P S B_{-} C_{43}=W_{43}^{3} \bullet D_{43}^{T} \\
& =0.163 \times E C N+0.540 \times E T I+0.297 \times P E D \\
& S R D_{-} C_{44}=W_{44}^{3} \bullet D_{44}^{T} \\
& \quad=0.333 \times V Q R+0.667 \times P S R \\
& D N O \_C_{45}=W_{45}^{3} \bullet D_{45}^{T} \\
& =0.540 \times P E M+0.297 \times E M M+0.163 \times E S E \\
& P O M_{-} C_{46}=W_{46}^{3} \bullet D_{46}^{T} \\
& =0.196 \times R P C+0.311 \times P L S+0.493 \times T L R
\end{aligned}
$$

\section{Conclusions}

The paper designed the post-evaluation index system of the energy trusteeship project of the regional distribution system, and then calculated the weight after collecting evaluation data of the relative importance of evaluation index on basis of AHP. Finally, the post-evaluation mode of the energy trusteeship of regional distribution network was constructed. The research of the paper could provide the scientific evidence and reference for improving the investment efficiency of energy trusteeship project of regional distribution network in China.

\section{Acknowledgements}

This paper is supported by "Science and technology project funding by State Grid Corporation of China (Grant No 27KJ010501C1016320140000)".

\section{References}

[1] Yao Q P, Shi H. Study on the Implementation of Energy Custodian energy performance contracting Mode. Science \& Technology Innovation Herald, 2015, 6, pp. 33-35.

[2] Huang N, Lu B S. Research on energy saving service operation mode based on the power grid enterprises of energy trusteeship. Guizhou Electric Power Technology, 2014, 17, (3), pp. 26-18.

[3] Wang JM. Study on Integration Evaluation Method of Large Project Investment Results' Post Evaluation [J]. Engineering Economy, 2014, 9, pp.44-49.

[4] Ma D M. Study on evaluate method and application of accomplished rural power network construction and rebuilding projects. Beijing: BEIHANG University, 2003.

[5] Yang Y H, Xian-Dong L I. Study of Theory and Method for PostEvaluating of Wind Power. Journal of North China Electric Power University, 2008, 3, pp. 6-9.

[6] Guo X Z. The Transmission and Distribution Construction Project Postevaluation Model and Empirical Research. Beijing: North China Electric Power University, 2012.

[7] Wang G H, Zhou J. Methods exploration of projects post evaluation. Strategic Planning and Evaluation, 2004, 1, pp. 97-99.

[8] Tang H Z, Peng J C. Research on Synthetic and Quantificated Appraisal Index of Power Quality Based on Fuzzy Theory. Power System Technology, 2003, 27, (12), pp. 85-88.

[9] Cao M L. Analytic hierarchy process (AHP) to determine evaluation index weights and Excel calculation. Jiangsu Science \& Technology, 2012, (2), pp. 39-40.

[10] Lei L. Determining the Weight of Factors in Power Transmission Project Post-project Evaluation. Coal Technology, 2010, 29, (8), pp. 35-37. 